$15^{\text {th }}$ International Conference on

AEROSPACE SCIENCES \& AVIATION TECHNOLOGY,

$\boldsymbol{A S A T}$ - 15 - May 28 - 30, 2013, Email: asat@mtc.edu.eg,

Military Technical College, Kobry Elkobbah, Cairo, Egypt,

Tel: +(202) 24025292 -24036138, Fax: +(202) 22621908

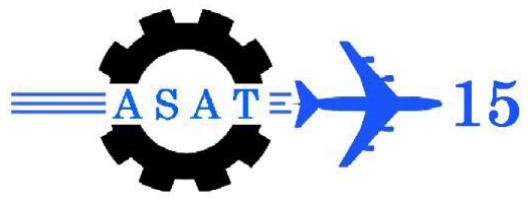

\title{
Gas Phase Air Cleaning Using Catalytic Oxidization
}

\author{
M. Tarraf*, M. Soltan ${ }^{\dagger}$, A. E. Elweteedy
}

\begin{abstract}
Life protection from air pollutants occupies the interest of the leaderships in the military forces. The main sources of pollutants are the mass destructive weapons (MDW) which include nuclear, biological, and chemical weapons (NBC). The popular technique used in air purification is the adsorption of chemical warfare agent (CWA) vapors on the surface of a solid sorbent, such as, charcoal granules. Another technique that increasingly took place in the last several years is the catalytic oxidation of the CWA in a catalytic reactor which is the subject of this research. The objective of this experimental work is to study the catalytic oxidation of toxic warfare agents which are represented as organic halids.1-2 Dichloroethane (DCE) is used as an imitator for the warfare agents which investigated over V2O5/TiO2based catalyst. The destruction of 1,2 DCE strongly depends on catalyst temperature and concentration of 1,2 DCE. The experiments were carried out at different catalyst temperatures 350,390 and $450^{\circ} \mathrm{C}$, and different concentration of $58.9 \mathrm{mg} / \mathrm{l}, 47.9 \mathrm{mg} / \mathrm{l}$ and $28.4 \mathrm{mg} / \mathrm{l}$. The highest conversion ratio $(78.75 \%)$ was obtained for initial concentration of $28.4 \mathrm{mg} / \mathrm{l}$ and catalyst temperature of $450^{\circ} \mathrm{C}$.
\end{abstract}

Keywords: Air purification, mass destructive weapons, catalytic oxidization.

\section{Nomenclature}

Q volumetric flow rate, $\mathrm{m}^{3} / \mathrm{h}$

$\mathrm{S} \quad$ cross section, $\mathrm{ft}^{2}$

$\mathrm{t}_{\mathrm{r}} \quad$ time, $\mathrm{h}$

V air velocity, $\mathrm{ft} / \mathrm{s}$

\begin{tabular}{ll}
\multicolumn{1}{c}{ Abbreviations } \\
AC & Hydrogen Cyanide \\
Bg & Bacillus Globigii \\
CATOX/PTF & Catalytic Oxidation / Post-Treatment Filtration \\
CWA & Chemical Warfare Agent \\
DCE & Dichloroethane \\
GB & Sarin \\
GD & Soman \\
HD & Distilled Mustard \\
MD & Methyldichloroarsine \\
MDW & Mass Destructive Weapon \\
MEK & Methyl Ethyl Ketone \\
NBC & Nuclear, Biological and Chemical
\end{tabular}

Syrian Armed Forces, Syria.

$\dagger$ Egyptian Armed Forces, Egypt.

* Egyptian Armed Forces, Egypt., aelweteedy@yahoo.com. 


\section{Introduction}

The problem of air purification was raised when pollutants, discharged from various sources, attained levels which formed serious threat for plant, animal, and human beings. These sources are: power plants, chemical industry, cement industry, exhaust gases from automotive transport, ships, airplanes, etc.

Additional kinds of pollutants appeared when various kinds of mass destructive weapons (MDW) were used. MDWs include nuclear, biological and chemical (NBC) weapons.The basic destructive effects of nuclear burst are: air pressure wave, light rays, penetrating radiation and radioactive contamination of terrain. The radioactive dust and aerosol are the most dangerous consequences in the period after the nuclear burst, because they form the basic contaminants to be removed from air in this case. Chemical warfare agents and biological weapons are very effective means at present especially if they affect unprotected manpower due to their extremely high toxicity or their capability to develop dangerous diseases of various characters. Chemical weapons also contaminate terrain, equipment and armament, thus causing difficulties of their employment during a combat action. Their mission consists in decreasing combat activity of manpower or in total exhaustion of soldiers. The chemical and biological warfare agents can be applied in form of splashes, aerosols or vapors. This depends on the way of their transportation to the target; shells, rockets, bombs, aerosol generators, etc.

Because of the reasons mentioned above, the problem of life protection occupies the central interest of the governments overall the world. For this purpose, and using the most developed scientific and technological achievements, the military research establishments in different countries studied the destructive and lethal effects of nuclear, biological, and chemical weapons and put appropriate solutions to protect man's life. So, many types of protection means began to appear. In general, these means are divided into two basic groups: individual and collective protection means.

Since nuclear and biological contamination is produced mainly due to solid or liquid aerosol particles, $99 \%$ of this contamination can be removed through the mechanical filtration process. Consequently, experimental work on this study will concentrate on the removal of the chemical warfare agents.

This paper deals with the technique that increasingly took place for air purification in the last several years which is the catalytic oxidation of the CWA in a catalytic reactor [1].

By definition, a catalyst is not physically or chemically altered as a result of a reaction. Catalysts are often composed of very stable, specialized materials, including noble metals like platinum. The principle of catalytic oxidation is being used for many purposes [2].

Catalytic oxidation process occurs in what called catalytic converter. The common form of catalytic converter consists of a monolith in a honeycomb configuration to provide the necessary surface area and a top layer of deposited catalyst metals [3].

\section{Literature Review}

The catalytic oxidation / post-treatment filtration (CATOX/PTF) system destroys greater than 99.9999\% of agents with only carbon dioxide and water as products for multiple attacks without maintenance. A 1994 study estimated that CATOX/PTF has 10 times less cost during a 1-year wartime period compared to traditional carbon filters. Since then, the catalyst activity 
and PTF capacity has been increased by 15 times. The CATOX operating temperature and residence time are sufficient to sterilize biological agents, which reduces the required particle filtration efficiency. Benefits occur when the CATOX/PTF is integrated with an environmental control system (ECS) [2].

In military-funded programs since 1964, CATOX has demonstrated complete destruction of agents. A $400 \mathrm{cfm}$ air conditioning unit was integrated with a CATOX collective protection system, which was challenged with GB over 82 hours. The three test rats survived breathing the output air. In separate tests, there were no surviving Bacillus globigii (B.g.) spores. Various catalyst formulations were tested for the destruction of agents GB, GD, VX, AC, HD, Lewisite, and the simulant DMMP with abnormally high agent concentrations in humid air for 4,000 hours at $250^{\circ} \mathrm{C}$. This was the first study to use monolithic catalysts instead of packed beds. The CATOX operating temperature and residence time are sufficient to sterilize biological agents. Under these conditions during MUST program testing, no Bacillus globigii (B.g.) spores survived. Similar results were recently obtained by MesoSystems Inc. in a DARPA-funded program using both B.g. and bacillus thermophillus, indicating that anthrax spores would also be destroyed. Thermal sterilization is the preferred method in the medical and food processing industries [2]. Many researches were performed on the catalytic oxidation of volatile organic compounds, and here are some of them:

Pt impregnated metallic monoliths prepared from anodized aluminum foils were tested to study their catalytic activity in complete oxidation of volatile organic compound (VOC) mixtures. The VOCs oxidized were 2-propanol, toluene, methyl ethyl ketone (MEK), acetone and their mixtures. Complete oxidation was obtained in all cases except for the case of 2propanol, where acetone was found as an oxidation intermediate. Even if the adsorption of the VOC on the $\mathrm{Al} 2 \mathrm{O} 3$ is governed by its polarity, the reactivity is mainly affected by the competition of the oxygen atoms chemisorbed on the Pt particles [4].

The catalytic oxidation of trichloroethylene (TCE) and trichloromethane (TCM) oxidized alone and in two-component mixtures with selected volatile organic compounds (VOCs) such as toluene, n-hexane, ethanol or acetone was investigated over a Pt-Pd-based catalyst on a monolithic, metallic, $\gamma$-Al2O3-washcoated support. TCE and TCM were more difficult to oxidize than VOCs and temperatures of their 50\% conversion (T50\%) amounted to 420 and $330^{\circ} \mathrm{C}$, respectively. All the VOCs added were found to enhance the conversion of the two chlorinated compounds, decreasing $\mathrm{T} 50 \%$ by $20^{\circ} \mathrm{C}$, at the most, for TCM in the presence of toluene and by $50^{\circ} \mathrm{C}$ for TCE in the presence of acetone. Both the chlorinated compounds lowered the conversion of the VOCs added (except that of toluene), and this lowering was particularly distinct with n-heptane; they also raised the concentration of acetaldehyde formed during the oxidation of oxyderivative compounds [4].

The catalytic oxidation of dichloromethane (DCM, $1000 \mathrm{ppm}$ ) in wet air over PtHFAU catalysts differing by their Pt content (from 0 to $0.87 \mathrm{wt} . \%$ ), the $\mathrm{Si} / \mathrm{Al}$ ratio being constant and equal to 5. For a given temperature, the rate of DCM transformation is independent of the platinum particles size and of the platinum content. On the other hand, DCM oxidation into $\mathrm{CO}_{2}$ occurs through a bifunctional mechanism: DCM was firstly hydrolyzed into $\mathrm{HCl}$ and formaldehyde on the Bronsted acid sites of the support. Afterwards, formaldehyde was oxidized into $\mathrm{CO}_{2}$ and $\mathrm{H}_{2} \mathrm{O}$ on the platinum sites [2].

The Pt/HFAU(47) catalyst suffered some deactivation in long duration experiments, probably as a result of coke accumulation. It was found that there is an optimal oxygen partial pressure in the feed: at low oxygen content the accumulated coke compounds are less oxidized; at high 
oxygen contents platinum oxidation can occur. The presence of water vapor did not have a major effect on the catalyst performance; however, the presence of o-xylene inhibited the oxidation of MIBK, while the oxidation of o-xylene was not affected [5].

A systematic investigation of the oxidation of 1,2-dichlorobenzene (o-DCB) was conducted over a series of vanadia/titania catalysts with different V2O5 loadings (i.e. 0.8, 3.6 and 5.8 wt $\%$ ). The $\mathrm{TiO}_{2}$ support was also found to be active for this reaction, but its activity was significantly lower than that of the surface vanadia species. Reaction rates per vanadium atom (i.e. turnover frequencies) were calculated for these catalysts and found to be independent of the vanadia coverage [6].

\section{Experimental Work}

\subsection{Introduction}

The objective of this experimental work is to study the catalytic oxidation of toxic warfare agents which are represented as organic halides and to extract the decomposition characteristics of these agents (the relation between the decomposition efficiency and any other parameter related to catalytic oxidation process, such as, air flow rate, concentration, oxidation temperature, etc). 1-2 DCE will be used as an imitator for the warfare agents, which are mostly alkylhalides.

\subsection{Chemicals and Materials}

All chemicals used in this experimental work are pure and used without any additional purification. Table 1 shows these chemicals.

Table 1 The chemicals used in experiments

\begin{tabular}{c|c|c|c|c}
\hline \hline No. & Chemicals & $\begin{array}{c}\text { Chemical } \\
\text { formula }\end{array}$ & Grade & Supplier \\
\hline 1 & $1,2 \mathrm{DCE}$ & $\mathrm{C} 2 \mathrm{H} 4 \mathrm{Cl} 2$ & $66.6 \%$ & TEDIA COM \\
\hline 2 & phenolphthalein & $\mathrm{C} 20 \mathrm{O} 4 \mathrm{H} 14 *$ & - & TEDIA COM \\
\hline 3 & Sodium carbonate & Na2CO3 & $99.5 \%$ & TEDIA COM \\
\hline \hline
\end{tabular}

In this experiment, the vapors of 1-2 DCE will be injected into an air stream to form a mixture, which in turn passes through a heated catalytic converter, where its decomposition occurs.

\subsection{The Test Rig Components and Instruments}

This test rig, Fig.1, consists of the following instruments and components: - blower (1), for preheating the catalytic converter before beginning the experiment; - an electric heater (2) to raise the air temperature from ambient to supposed temperature; - holding cylinder (3); - thermocouple (4) inserted into the catalytic converter (18) at its inlet for measuring the temperature of the intake mixture flow; - digital temperature indicator (5); - thermocouple (6) inserted into the catalytic converter (18) at its outlet for measuring the temperature of the outlet mixture flow; - on-off valves (7), (15) for flow control; - scrubber with alkaline medium for capturing the decomposed hydrochloric acid (8), (13); - air blower (9); - an orifice meter (10) for measuring the pressure drop, which is used for calculating the velocity 
of the air flow, consequently the volumetric flow rate; - digital manometer (12) for measuring pressure drop between the inner space of the orifice meter and the ambient air; - compressor (14) with variable pressure outlet to form an overpressure in scrubber (13) and enforce the vapors to flow into the heating cylinder; - on-off air valves (17), (20); - water bath electric plate (16) with adjustable temperature to evaporate the chemical substance poured in scrubber (13), this plate enables a temperature variation of the water in the bath between 40 and $100^{\circ} \mathrm{C}$; - catalytic converter (18) "NAT CA 6904 0407, American made", Fig. 2, in which the vapors of the chemical substance are decomposed, this converter consists of $0.8 \% \mathrm{~V} 2 \mathrm{O} / \mathrm{TiO} 2$ as catalyst on a honeycomb carrier; - water cooling heat exchanger (19) with open cooling cycle to decrease the temperature of the air-vapor mixture to ambient.

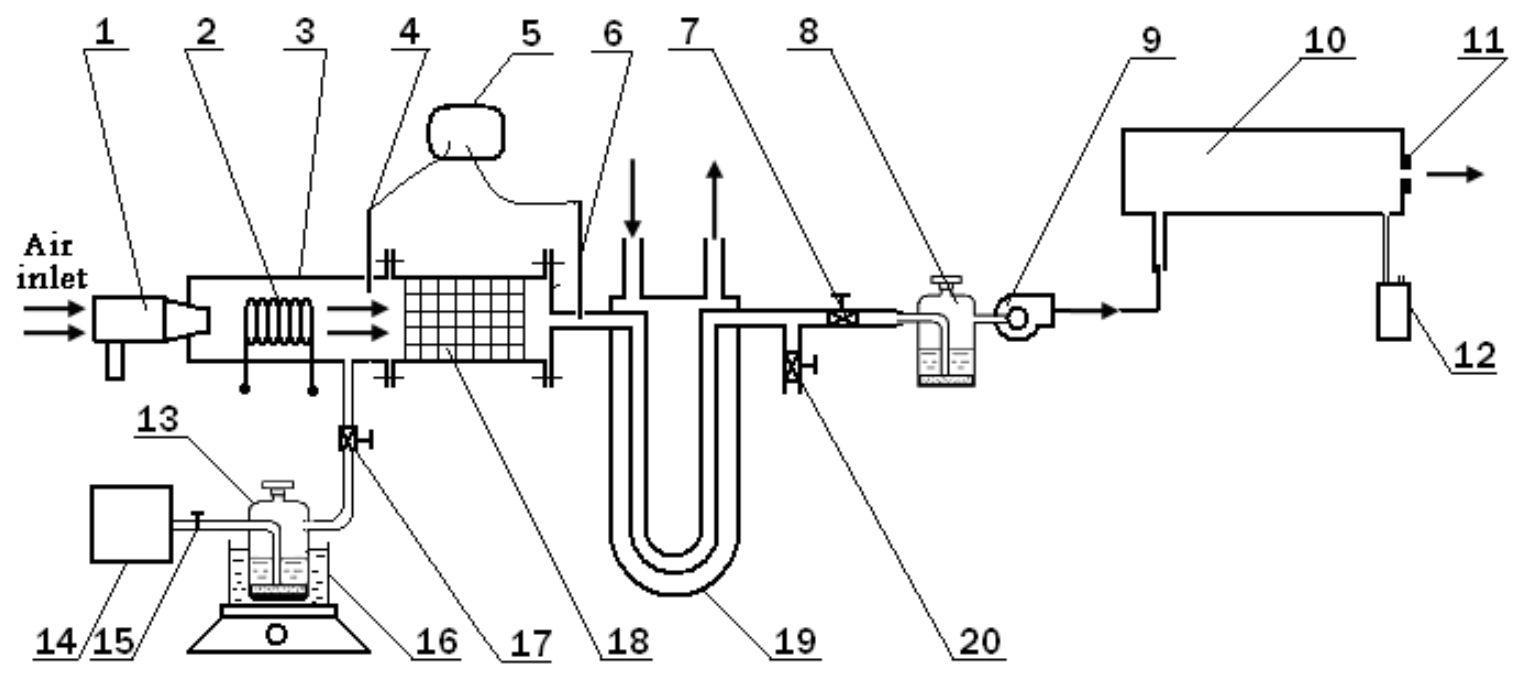

Fig. 1 The test rig used for determining the catalytic decomposition parameters of $1,2 \mathrm{DCE}$

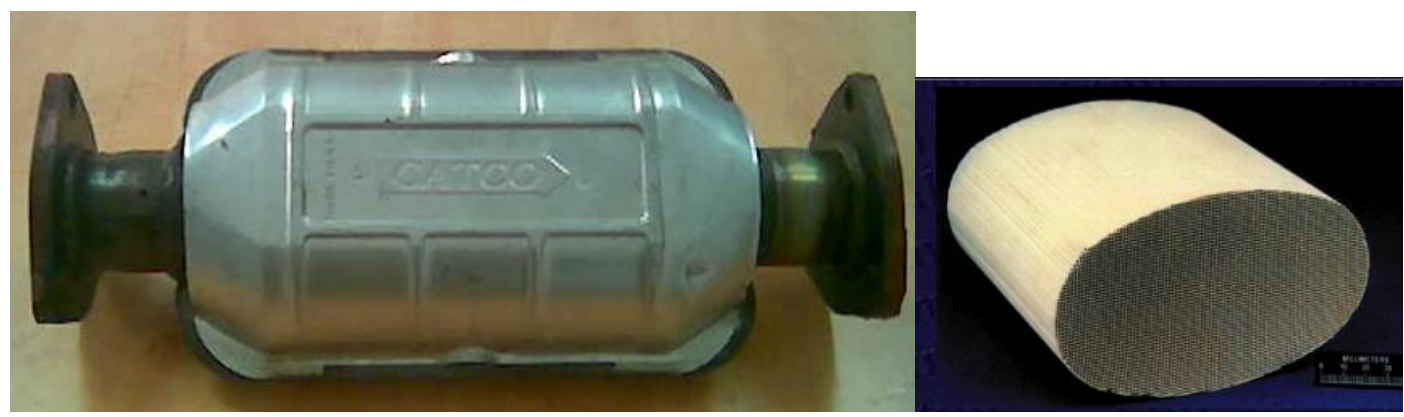

Fig.2 Catalytic converter

\subsection{Auxiliary Components}

Digital balance by which the weight of 1-2 DCE in scrubber (13) is determined at the beginning and at the end of the test; measuring glass graduated cylinder from 1 to $500 \mathrm{ml}$; potentiometer to control heat delivered to air flow.

\subsection{Test Procedure}

By using the digital balance, weight $0.5 \mathrm{~g}$ of sodium carbonate. Dissolve it in $150 \mathrm{ml}$ of distilled water in the graduated cylinder, and add a few droplets of phenolphthalein, as 
indicator. Thus, the obtained solution is a pink color alkaline solution. Pour this solution in scrubber (8) and fix the former in its position in the system.

Pour a certain amount (about $480 \mathrm{~g}$ ) of 1-2 dichloroethane in scrubber (13) and put the former in the water bath (16). Turn-on the electric plate till the temperature in scrubber (13) attains the supposed. To get precise readings, the amount of the liquid in scrubber (13) and the level of the water in water bath must be held constant, to guarantee a constant evaporation rate.

In order to heat up the system to a steady state temperature, valves (7) and (17) should be closed and valve (20) should be opened.

Turn-on the air blower (1) for preheating, until the supposed temperature of the catalytic converter is attained on the indicator (4). The temperature of the air flow is controlled by turning the wheel of the potentiometer right or left, thus, increasing or decreasing the voltage on the terminals of the thermal resistance (2).

When the temperature of the catalytic converter (18) becomes stable at the supposed value, open the valves (7) and (17), close the valve (20) and turn-on the air blower (9) with continuous adjustment of the catalytic converter temperature by the potentiometer's wheel.

The process continues, until the liquid in scrubber (8) becomes colorless. At this moment, the time of the experiment, the readings $\mathrm{T}_{\text {in }}$ and $\mathrm{T}_{\text {out }}$ (the temperatures at the inlet and outlet of the catalytic converter) and the pressure drop $\Delta \mathrm{P}$ between the gas in the orifice meter (10) and the ambient air temperature must be recorded. The system is turned-off.

Scrubber (13) to be weighted after the test to determine $(\Delta \mathrm{m})$ the evaporated amount of $1-2$ dichloroethane.

\subsection{Calculations}

From the measured value of $\Delta \mathrm{P}$, the velocity of the air through air box can be calculated and from the values of air velocity and cross sectional area of the orifice, $S$ the volumetric flow rate, $\dot{Q}$ is calculated.

$$
\dot{Q}=S . V
$$

From the geometrical parameters of the catalytic converter, residence time is calculated

$$
t_{r}=\frac{V_{c o n v}}{\dot{Q}}
$$

where:

$V_{\text {conv }}=1.307 l:$ the volume of the catalytic converter.

The theoretical amount of hydrochloric acid needed for neutralizing the sodium carbonate solution is calculated.

The decomposition efficiency $\eta$ is calculated. 


\section{Results and Analysis}

Using the test rig shown on Fig. 1, several experiments were performed to demonstrate the catalytic oxidation characteristics of 1-2 DCE at different catalyst temperature 350, 390, and $450^{\circ} \mathrm{C}$ for different constant evaporation temperature of $1,2 \mathrm{DCE}, 70^{\circ} \mathrm{C}, 60^{\circ} \mathrm{C}, 50^{\circ} \mathrm{C}$ and different concentration.

Samples of the results are plotted in the following figures:

Figure 3 shows the variation of the conversion ratio of $1,2 \mathrm{DCE}$ at catalyst temperature $350^{\circ} \mathrm{C}$ and evaporation temperature $70^{\circ} \mathrm{C}$ with respect to the air flow rate. It is clear that, the conversion ratio increases as the air flow rate increases, because the concentration of 1,2 DCE decreases.

Figure 4 shows the Influence of concentration ratio on conversion ratio at catalyst temperature $350^{\circ} \mathrm{C}$ and evaporation temperature $70^{\circ} \mathrm{C}$. It is clear that that, the conversion ratio decreases as the concentration of 1,2 DCE increases. This can be explained as follows: as the concentration increases, the decomposed amount of 1,2 DCE increases, what leads the conversion ratio to decrease.

Figure 5 shows the variation of conversion ratio with residence time at catalyst temperature $350^{\circ} \mathrm{C}$ and evaporation temperature $70^{\circ} \mathrm{C}$. It is clear that, the increasing of residence time is accompanied with decreasing of conversion ratio, because of the increasing of concentration.

Figure 6 shows the variation of the conversion ratio of 1,2 DCE at different catalyst temperatures and average concentration of $58.9 \mathrm{mg} / \mathrm{l}$ with air flow rate. It is clear that, at higher catalyst temperatures, the conversion ratio is displaced to higher values. This behavior is in harmony with the nature of catalytic oxidation process, which becomes more active at higher temperatures.

Figure 7 shows the variation of conversion ratio at different catalyst temperatures and average concentration of $47.9 \mathrm{mg} / \mathrm{l}$ with air flow rate. The level of the conversion ratios is higher than that shown on Fig. 6, due to lower concentration of 1,2 DCE.

Figure 8 shows the variation of Conversion ratio at different catalyst temperatures and average concentration of $28.4 \mathrm{mg} / \mathrm{l}$ with air flow rate. The level of the conversion ratios is higher than that shown on Fig. 6, due to lower concentration of 1,2 DCE.

Figure 9 shows the conversion ratio versus catalyst temperature at different concentrations of 1,2 DCE and fixed air flow rate $72.5 \mathrm{l} / \mathrm{min}$. The figure shows that, the conversion ratio increases with increasing the catalyst temperature and with decreasing the concentration of 1,2 DCE.

Figure 10 shows the max conversion ratio versus air flow rate at $50^{\circ} \mathrm{C}$ evaporation temperature for different catalyst temperatures. The maximum values of conversion ratio lie between $75-77.51 / \mathrm{min}$ for any catalyst temperature located within $350-450^{\circ} \mathrm{C}$. 


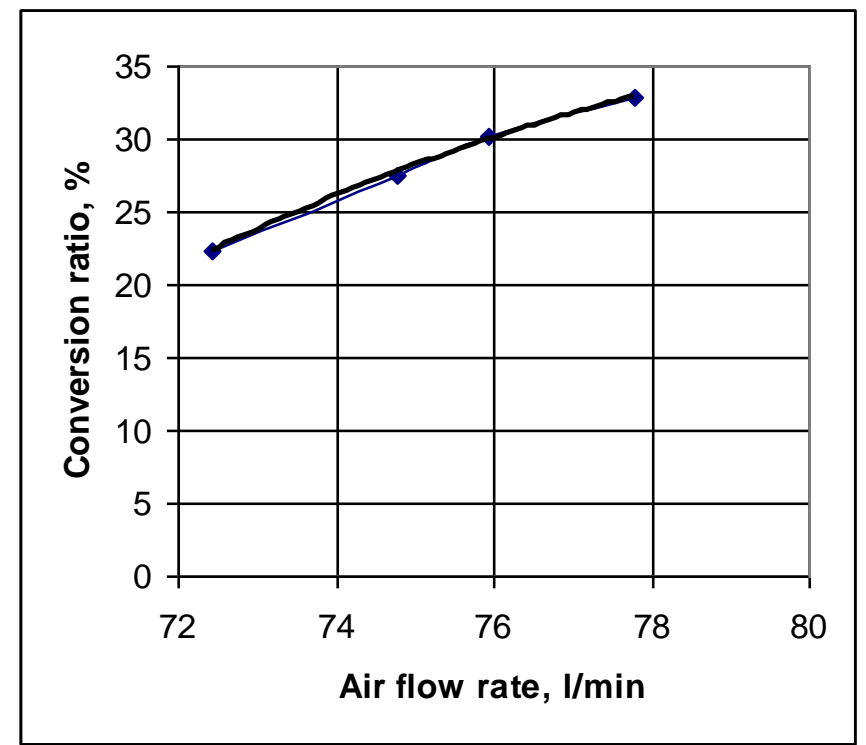

Fig. 3 The conversion ratio of 1,2 DCE at catalyst temperature $350^{\circ} \mathrm{C}$ and evaporation temperature $70^{\circ} \mathrm{C}$

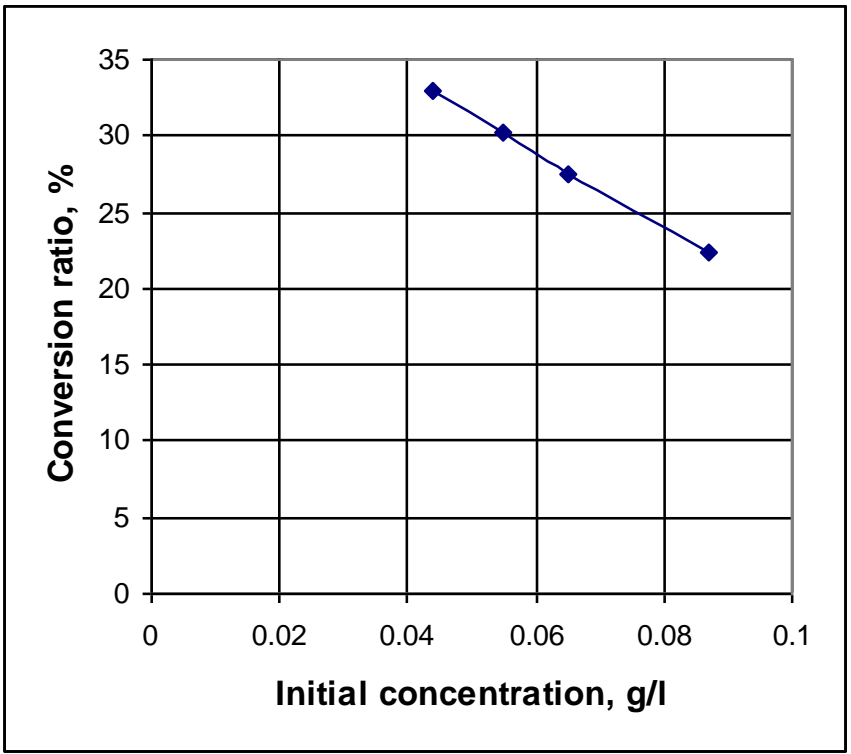

Fig. 4 Influence of concentration on conversion ratio at catalyst temperature $350^{\circ} \mathrm{C}$ and evaporation temperature $70^{\circ} \mathrm{C}$ 


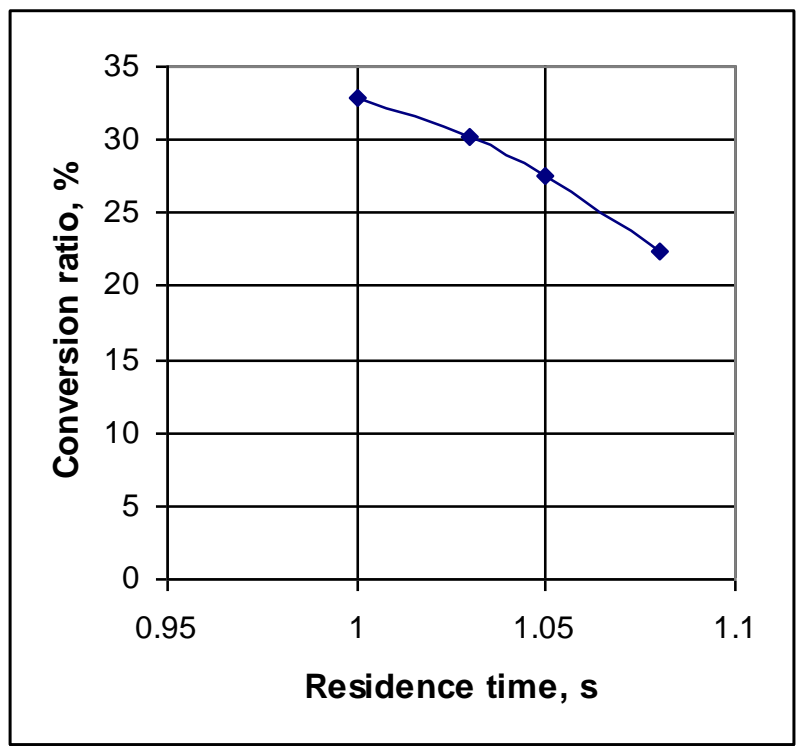

Fig. 5 Variation of conversion ratio with residence time at catalyst temperature $350^{\circ} \mathrm{C}$ and evaporation temperature $70^{\circ} \mathrm{C}$

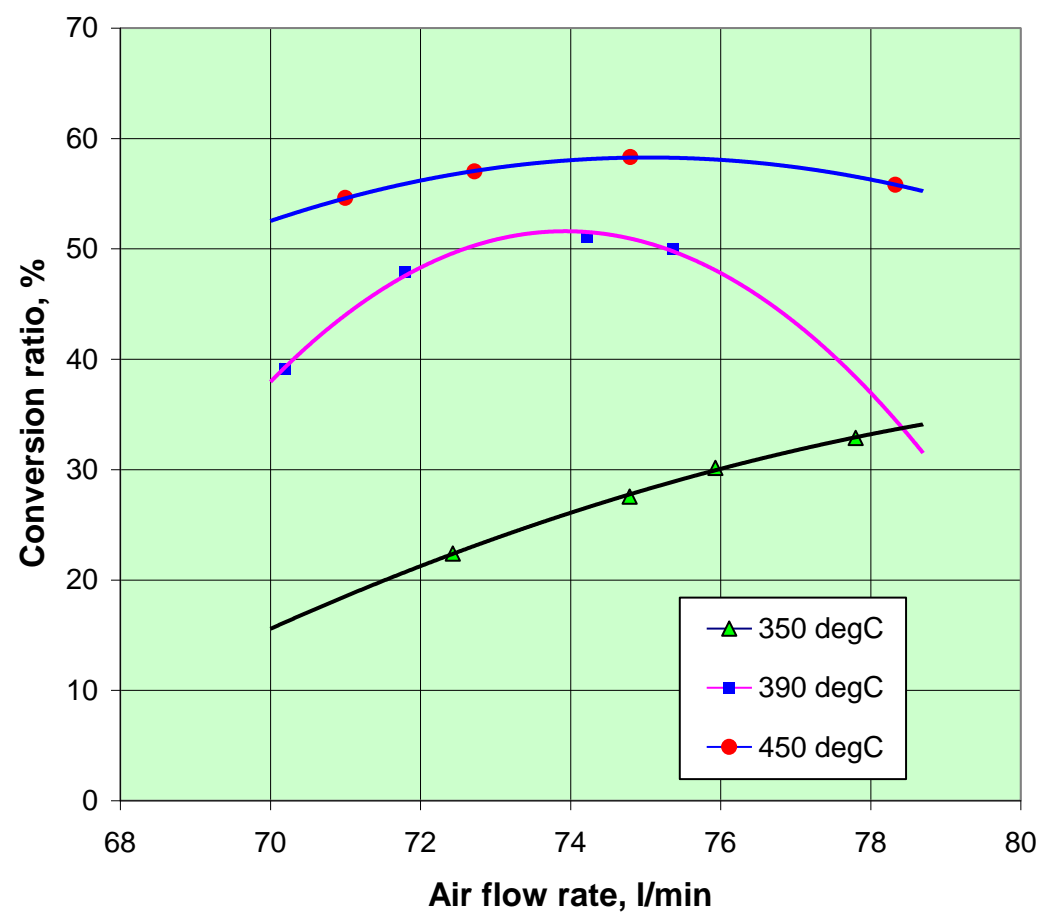

Fig. 6 The conversion ratio of 1,2 DCE at different catalyst temperatures and average concentration of $58.9 \mathrm{mg} / \mathrm{l}$ 


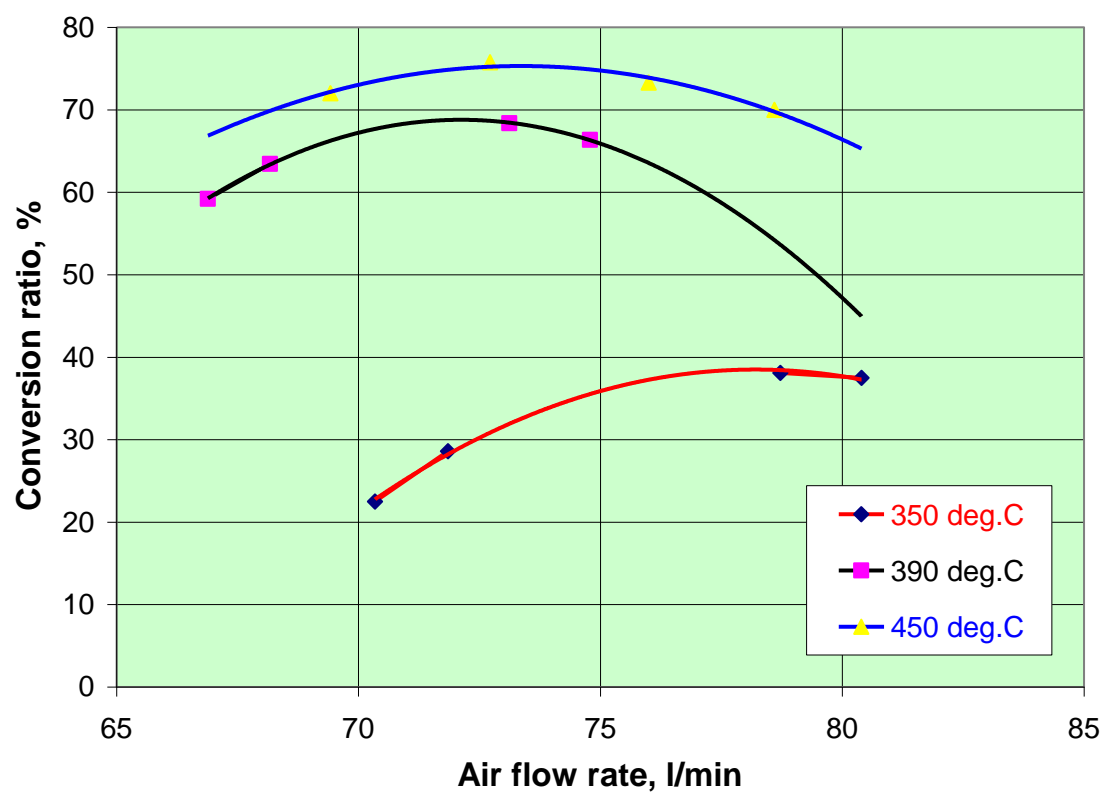

Fig. 7 Conversion ratio at different catalyst temperatures and average concentration of $47.9 \mathrm{mg} / \mathrm{l}$

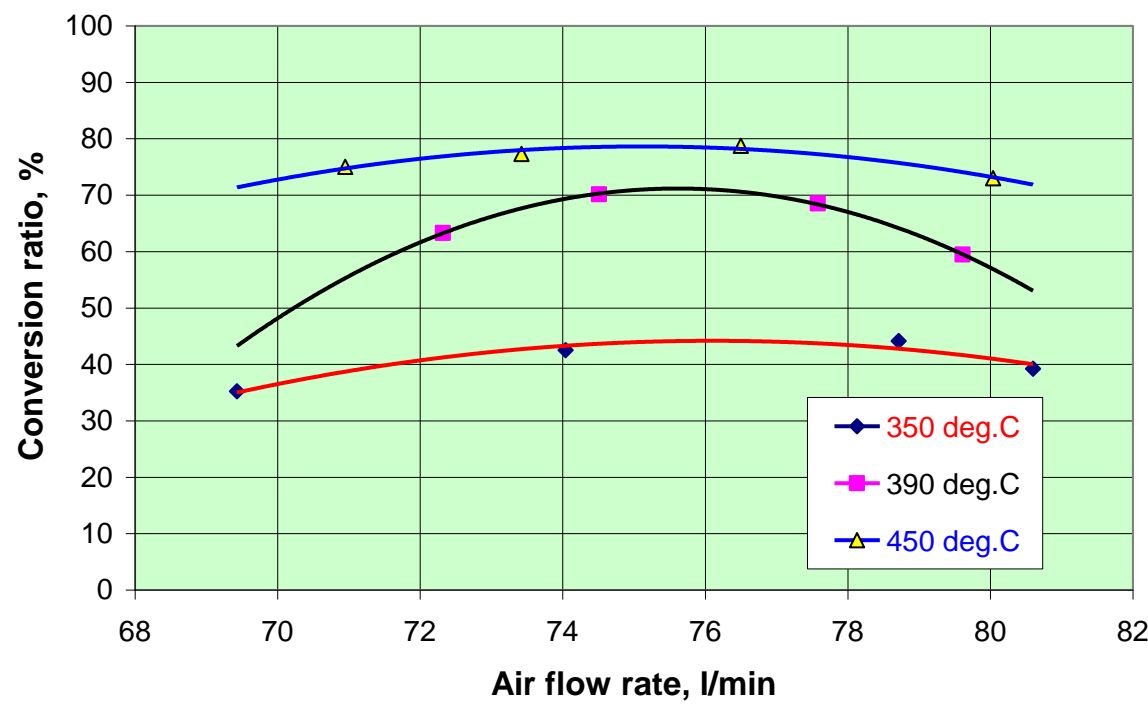

Fig. 8 Conversion ratio at different catalyst temperatures and $28.4 \mathrm{mg} / \mathrm{l}$ concentration of 1,2 DCE 


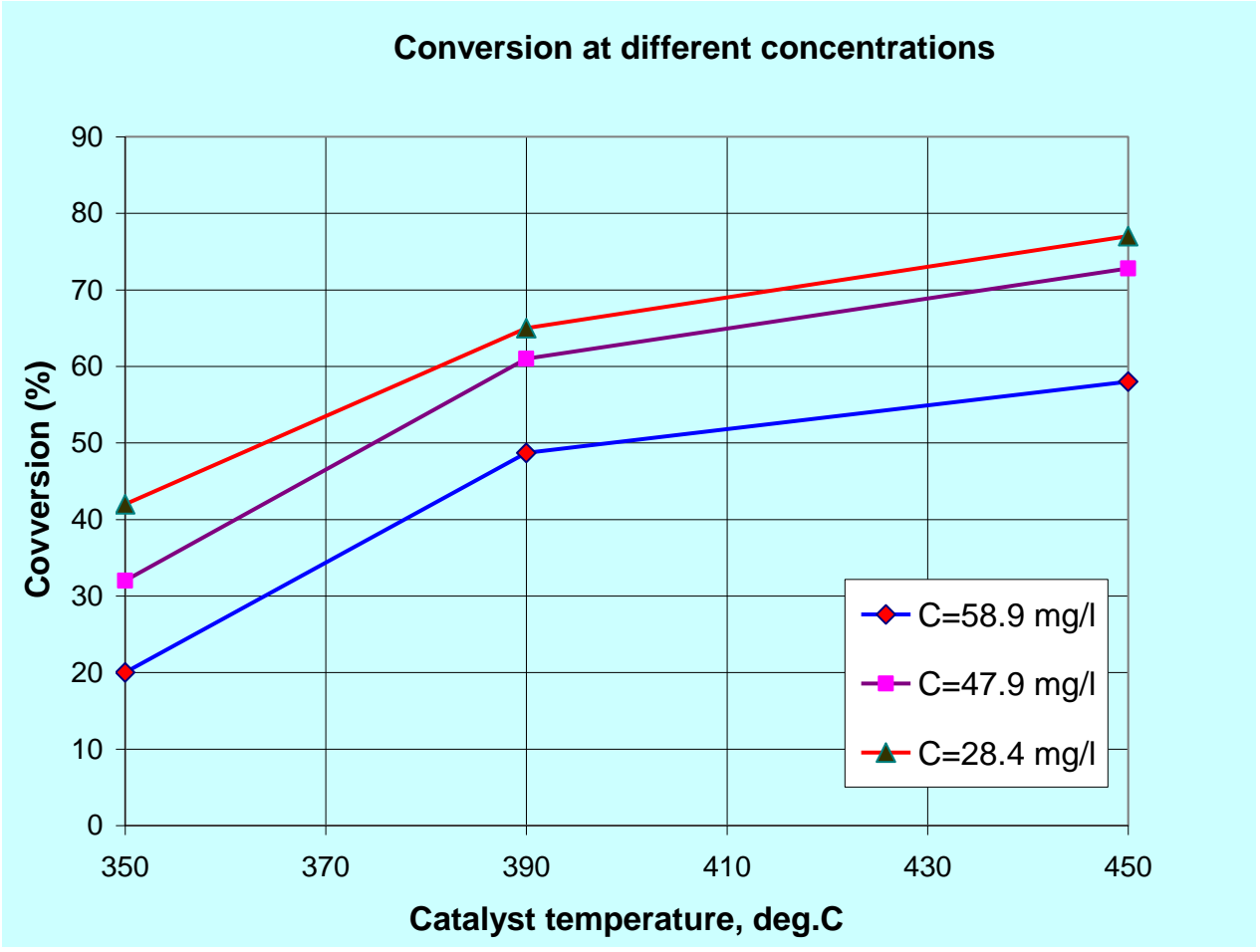

Fig. 9 The conversion ratio versus catalyst temperature at different concentrations of 1,2 DCE and fixed air flow rate

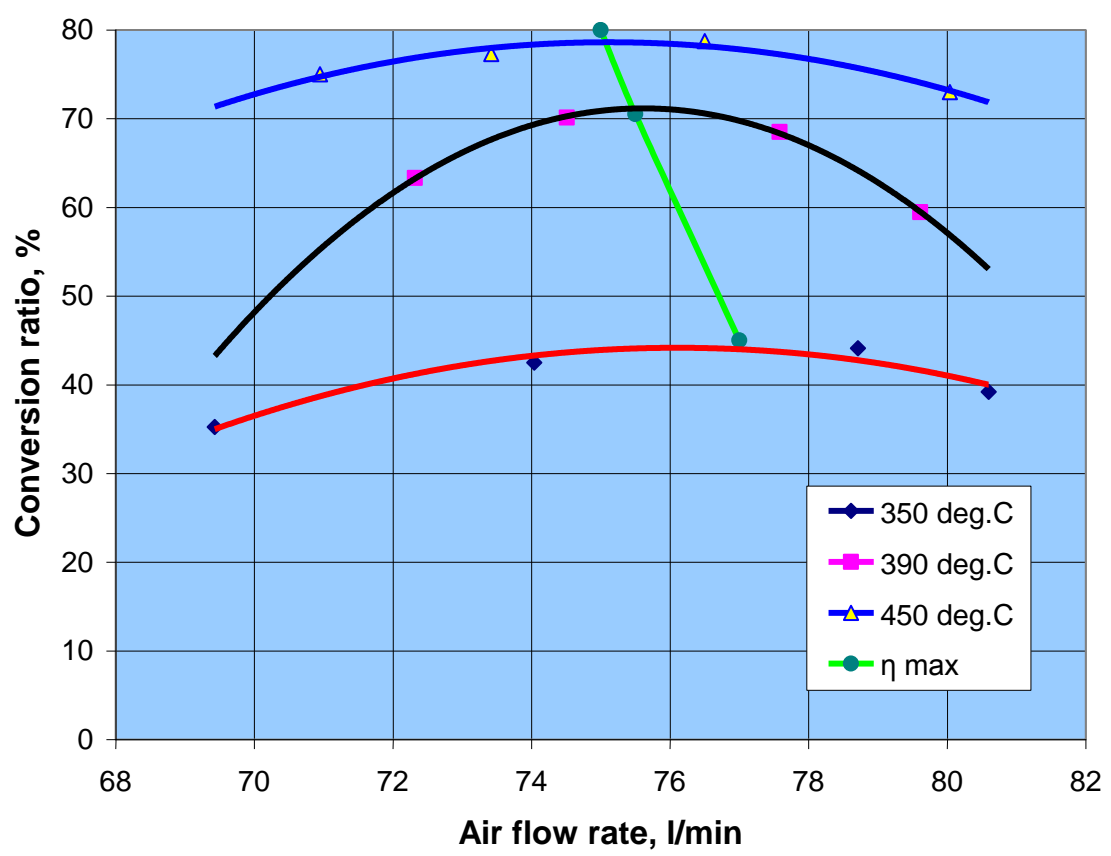

Fig. 10 Max conversion ratio versus air flow rate at $50^{\circ} \mathrm{C}$ evaporation temperature. 


\section{Conclusion}

The catalytic oxidation of 1,2 DCE has been investigated over V2O5/TiO2-based catalyst. The destruction of 1,2 DCE strongly depends on catalyst temperature and concentration of 1,2 DCE.

It was found that, for catalyst temperatures 350,390 and $450^{\circ} \mathrm{C}$ with initial concentration of $58.9 \mathrm{mg} / \mathrm{l}$, the highest corresponding conversion ratios were $32.87,51.12$ and $58.3 \%$ respectively.

At catalyst temperatures 350,390 and $450^{\circ} \mathrm{C}$ with initial concentration of $47.9 \mathrm{mg} / \mathrm{l}$, the highest corresponding conversion ratios were $38.1,68.36$ and $75.75 \%$ respectively.

At catalyst temperatures 350,390 and $450^{\circ} \mathrm{C}$ with initial concentration of $28.4 \mathrm{mg} / \mathrm{l}$, the highest corresponding conversion ratios were $44.12,70.12$ and $78.75 \%$ respectively.

The highest conversion ratio $(78.75 \%)$ was obtained for initial concentration of $28.4 \mathrm{mg} / \mathrm{l}$ and catalyst temperature of $450^{\circ} \mathrm{C}$.

The catalytic oxidation process can be used in collective protection shelters to destruct the chemical warfare agents and convert them into nontoxic products. This requires a great number of experiments on various catalysts within wide specter of conditions to attain the optimum catalyst combination and temperature, at which the conversion ratio will be very close to $100 \%$.

\section{References}

[1] "Guidance for Filtration and Air-Cleaning Systems to Protect Building Environments from Airborne Chemical, Biological, or Radiological Attacks", Department of Health and Human Services, 2003.

[2] Nerea Burgos, Mar'1a Paulis, M. Mirari Antxustegi, Mario Montes "Deep oxidation of VOC mixtures with platinum supported on Al2O3/Al monoliths", Elsevier, 2001.

[3] Kirk-Othmer, "Encyclopedia of Chemical Technology-volume 9", John Wiley \& Sons. 1976.

[4] Peter M. Michalakos, Norman Van Den Bussche, Belinda Foor, Mark Koch, and Mariola Proszowski, "Catalytic oxidation for collective protection", Honeywell International.

[5] Anna Musialik-Piotrowska, "Destruction of trichloroethylene (TCE) and trichloromethane (TCM) in the presence of selected VOCs over Pt-Pd-based catalyst", Elsevier, 2006.

[6] L. Pinard, J. Mijoin, P. Ayrault, C. Canaff, P. Magnoux, "On the mechanism of the catalytic destruction of dichloromethane over Pt zeolite catalysts", Elsevier, 2004. 